http://ejtr.vumk.eu

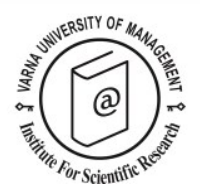

\title{
The attitudes of Thai hosts towards western volunteer tourists
}

\author{
Raweewan Proyrungroj ${ }^{1 *}$
}

Received: 05/01/2015 Accepted: 27/03/2015

\footnotetext{
${ }^{1}$ Tourism Management Programme, International College, Suan Sunandha Rajabhat University, 1 U-Thong Nok Road, Dusit, Bangkok, Thailand, 10300; tel: 02-1601200 ext. 27, e-mail: raweewan.pr@ssru.ac.th, miss_raweewan_18@yahoo.com

* Corresponding author
}

\begin{abstract}
This study examines the attitudes of Thai hosts towards Western volunteer tourists who were on volunteer vacation at the Home and Life orphanage. An interpretive paradigm utilising a combination of qualitative data collection methods (semi-structured, in-depth interviews and participant observation) was conducted with twenty resident members of Thai Muang sub-district who acted as the host of the volunteer tourists. The analysis of the data revealed that all respondents portrayed positive attitudes towards volunteer tourists, based upon two main factors: the volunteer tourists' conduct and performance; and the perceived benefits they gained from the work of these tourists. The opportunity for the local children to learn English with English native speakers was cited as the most significant benefit. However, the respondents also had concerns about some aspects of the volunteer tourists' behaviour and perceived under-performance, which was found to be mainly the result of cultural differences. In addition, it was found that there are mixed views regarding the volunteer tourists: some respondents perceived them as special type of tourist, whereas some viewed them as being non-tourists.
\end{abstract}

(C) 2015 Varna University of Management. All rights reserved

Keywords: Thai hosts' attitudes; influencing factors, Western volunteer tourists, host-tourist relationship

Citation: Proyrungroj, R. (2015) The attitudes of Thai hosts towards western volunteer tourists. European Journal of Tourism Research 11, pp. 102-124

\section{Introduction}

Volunteer tourism is a relatively new form of tourism (Ackerberg \& Prapasawudi, 2009; Tomazos \& Butler, 2009). It is a phenomenon originating in Western countries, mainly Britain and Europe, and then expanding to other regions including Australia and the United States. Now it is a growing trend among participants in Eastern or developing countries such as Asia and Africa as well (Alexander, 2012; Lo \& Lee, 2011; Wearing \& McGehee, 2013).
According to Tourism Research and Marketing (TRAM, 2008), volunteer tourism has experienced phenomenal growth over the past two decades: approximately 120,000 travellers from the United States and the United Kingdom take a volunteer trip abroad annually. However, TRAM (2008) also notes that this number is based only on individuals who take trips through volunteering organisations; therefore, the number of volunteer tourists could be much higher than this estimate, because there is also a great number of people taking volunteer trips 
independent of volunteer organisations, representing a very large proportion of all volunteer tourists.

The phenomenal growth of volunteer tourism is the result of a combination of factors. Among these are the growth of mass tourism (Callanan \& Thomas, 2005; Tomazos \& Butler, 2009; TRAM, 2008) and the power of the media that exposes people to other, poorer, societies, thereby inspiring them to do something worthwhile for those societies (Callanan \& Thomas, 2005). In addition, natural disasters which have occurred in many regions also play an important role in the growth of volunteer tourism. The industry report 'Volunteer Travel Insights 2009' points out that the September $11^{\text {th }}$ incident in the United States in 2001 and the Boxing Day tsunami that hit many countries in Southeast Asia in 2004 have made a number of travellers more aware of opportunities to take a holiday that involved volunteering (Nestora, Yeung \& Calderon, 2009).

Moreover, Wearing \& McGehee (2013) also add that other factors, such as a reduction in barriers to travel, an increase in the population in the middle class in many developing countries, and the desire of the middle class to gain more unusual and meaningful tourism experiences, also contribute to the growth and popularity of volunteer tourism.

The phenomenon of volunteer tourism has caught the interest of researchers and practitioners, who have begun to investigate this issue (Wearing, 2001).Existing studies argue that volunteer tourism has been viewed as an ideal form of tourism with no or few negative impacts (e.g. Broad, 2003; Brown, 2005; Brown\& Morrison, 2003; Stoddart \& Rogerson, 2004). A number of studies report good intentions of volunteer tourists to take part in volunteer tourism activities (e.g. Brown, 2005; Carter, 2008; Chen \& Chen, 2011; Lo \& Lee, 2001; Sin, 2009; Wearing, 2001) as well as positive experiences they have gained from such participation (e.g. Broad, 2003; Harlow \& Pomfret, 2007; Lo \& Lee, 2001; Mclntosh \& Zahra, 2007). However, some recent studies have begun to point out the potential negative impacts of volunteer tourism. For example, Guttentag (2009) and Vrasti (2013) argue that volunteer tourism is a new form of colonialism, where people from developed nations take advantage of the poverty and unfortunate circumstances of people in developing nations, and this form of tourism creates another type of dependency between developed and developing nations.

In addition, it is apparent that among the existing literature, the perspective of the volunteer tourists has received overwhelming interest, compared to the perspectives of the host communities where volunteer tourism takes place. The significance of understanding host communities' attitudes towards tourists lies primarily in the general acceptance that host communities are key players in the success or failure of sustainable tourism development (Ap, 1992; Chandralal, 2010; Taylor, 1995). This is because residents in these communities have permanent status in the place where tourism activities take place and are in a position to either provide on-going support for, or to hinder the development of, tourism (Andereck \& McGehee, 2008; Ap, 1992).

Studies of host communities' attitudes towards volunteer tourists are still very limited, especially those using a qualitative approach. As noted by Fredline \& Faulkner (2003), and McGehee \& Andereck (2004), residents in host communities are not a homogeneous group of people, but diverse, and therefore, likely to vary greatly in their attitudes. Qualitative studies on this topic are, therefore, required, so that rich information can be obtained. Addressing the gap in the literature, this study examines the attitudes of Thai hosts towards Western volunteer tourists with the aim of contributing to the literature on volunteer tourism, especially in the context of volunteer tourism undertaken by Western volunteer tourists in developing countries.

\section{Literature review \\ Volunteer tourism \\ Definitions of volunteer tourism}

The term 'volunteer tourism' has been defined differently by various authors and to date there is no consensus on its definition. The following are examples of definitions of volunteer tourism that have been widely cited in existing 
literature. Wearing (2001: 1) defines volunteer tourism as

\section{[T]hose tourists who, for various reasons, volunteer in an organised way to undertake holidays that might involve aiding or alleviating the material poverty of some groups in society, the restoration of certain environments or research into aspects of society or the environment.}

McGehee \& Santos (2005: 760) state that volunteer tourism refers to "utilising discretionary time and income to go out of the regular sphere of activity to assist others in need". Corti, Marola and Castro (2010: 221) refer to it as

a kind of tourism based on
international, inter-social and
intercultural cooperation to maximise
the common good trying to get a
sustainable development. In order to
make that possible, volunteers offer
their time, knowledge, skills or financial
resources to benefit other people or
causes that need it.

All of the above definitions highlight the practice of volunteer tourists who engage in voluntary activities that potentially provide benefits to the host community. What is also reflected in these definitions is that volunteer tourism is a form of holiday or tourism that has a component of volunteering in the community at the destination the tourists visit.

\section{Main aspects of volunteer tourism}

The definitions of volunteer tourism mentioned above, together with a review of existing literature, suggest five main aspects of volunteer tourism, which include:

\section{(i) Volunteering and travelling}

Volunteer tourism can be considered a tourism activity or 'holiday' because it involves the temporary movement of individuals from their usual place of work or residence to other destinations during their free time.

\section{(ii) Goodwill}

The actions of the volunteer tourists are often considered to be out of goodwill or altruism and will potentially benefit other people (Broad, 2003; Callanan \& Thomas, 2005; Cortiet al., 2010; Gray \& Campbell, 2007; McGehee\& Santos, 2005; Wearing, 2001). This is closely linked to the concept of travel philanthropy, defined by Kepher-Gona (2008: 1) as "a response by travellers and travel companies to the needs of destinations where they visit or operate their business."

\section{(iii) Reciprocal benefits}

A number of studies(e.g. Broad, 2003; Brown \& Morrison, 2003; Lepp, 2009; McGehee \& Santos, 2005; Mclntosh \& Zahra, 2007; Ooi \& Laing, 2010; Raymond \& Hall, 2008; Sin, 2009; Uriely, Reichel, \& Ron, 2003; Wearing, 2001) argue that volunteer tourism is a mutually beneficial form of travel from which both the volunteer tourists and the host communities can benefit equally. For the volunteer tourists, the notion of self-development is repeatedly mentioned in existing literature (e.g. Broad, 2003; Harlow \& Pomfret, 2007; Jones, 2005; Lo \& Lee, 2011). These studies uniformly claim that volunteer tourism experiences facilitate the volunteer tourists to develop their abilities and skills in multiple ways.

As for the host communities, several studies (e.g. Broad, 2003; Morgan, 2010; Sin, 2010; Stoddart \& Rogerson, 2004) argue that the host communities where volunteer tourism takes place can gain a number of economic, social and environmental benefits from the work of volunteer tourists. In terms of economic-related benefits, according to Morgan (2010), the host communities can enjoy both direct and indirect benefits from volunteer tourism. The direct benefits include increased manpower and direct financial support through volunteering placements; and indirect benefits are increased local employment, supplementary revenue and improved facilities (e.g. schools and parks).

In terms of social-related benefits, volunteer tourism not only provides a free workforce and funds to the local communities where it takes place (Callanan \& Thomas, 2005; Mclntosh \& Zahra, 2007; Stoddart \& Rogerson, 2004; Wearing, 2001), but it can also provide a viable means of education for local people (Sin, 2010). Sin (2010: 987) uses the Chinese proverb, "Give a man a fish and you feed him 
for a day. Teach a man to fish and you feed him for a lifetime" to explain the significance of education-related projects offered by volunteer tourists to enable local people to rely on themselves rather than having to depend on the assistance offered by others. In addition, Wearing (2001) argues that volunteer tourism has the potential to promote the privileging of local culture and values. As for environmental benefits, volunteer tourism that takes place in nature-based destinations can help with the restoration and conservation of the environment in these destinations (Broad, 2003; Wearing, 2001).

\section{(iv) Cross-cultural exchange}

Volunteer tourism is also believed to provide great opportunities for direct, intense interaction and cultural exchange between volunteer tourists and host communities (Brown, 2005; Jones, 2005; Mclntosh \& Zahra, 2007; Zahra \& Mclntosh, 2007). This is because the volunteer tourists live and work in the host community and engage in the lives of the local people, which consequently allows them to directly observe and have engaging interactions with them (Broad, 2003).

\section{(v) Undertaken by Westerners in developing countries}

The notion that the world is divided into a rich, developed 'North' and a poor, developing 'South', where the former ought to be responsible and provide assistance for the latter because their privileges were gained at the expense of the latter (Silk, 2004; Sin, 2010), together with the notion that tourism is an effective means of transferring wealth from rich countries to poor countries (Kepher-Gona, 2008), underpins the concept of volunteer tourism. This is because this form of tourism is often perceived as a practice of people from developed or Western nations, who are generally wealthier with better skills and knowledge, travelling to provide assistance to people in developing countries who are poorer and less fortunate (Corti et al., 2010; Palacios, 2010; Richter \& Norman, 2010; Scheyvens, 2002; Simpson, 2005; Sin, 2009).

\section{Volunteer tourists}

Wearing (2001) defines volunteer tourists as persons who seek a tourist experience that provides reciprocal benefits for themselves and the host communities they visit. McGehee \& Andereck (2009) argue that volunteer tourists are not viewed as tourists by all the volunteer tourists and host communities. Similarly, Lyons (2003), Van der Meer (2007), and Wearing (2001) point out that some volunteer tourists are reluctant to identify themselves as traditional tourists. Moreover, Lepp (2009) also found that some volunteer tourists require some form of task or duty to differentiate them from conventional tourists.

As one of the main aspects of volunteer tourism is working without pay, the question of whether volunteer tourists should be considered volunteers or a type of tourist arises. A number of researchers and scholars (e.g. Broad, 2003; Brown, 2005; Gray \& Campbell, 2007; Jones, 2005; McGehee \& Santos, 2005; Mustonen, 2006; Raymond, 2007; Wearing, 2001; Zahra \& Mclntosh, 2007) argue that volunteer tourists should be considered a type of tourist, rather than volunteers.

According to Raymond (2007), one distinction between volunteer tourists and conventional volunteers is that being a 'volunteer tourist' involves a travel component. By implication, volunteer tourists are different from volunteers, in the sense that they do not only work, but also spend time in tourism or leisure activities. In other words, the combination of working and travelling distinguishes volunteer tourists from conventional volunteers. A further distinction is made by Tomazos \& Butler (2009), who highlight that volunteer tourists have to pay for travel, accommodation and food costs for their opportunity to work, just like tourists pay for a holiday, in contrast to conventional volunteers who do not pay or pay a nominal amount.

The motivation of volunteer tourists is a further category that can be used to differentiate them from conventional volunteers. Existing literature (e.g. Brown, 2005; Chen \& Chen, 2011; Lo \& Lee, 2011; Sin, 2009; Wearing, 2001) argues that volunteer tourists are driven by a desire to gain authentic and cross-cultural experiences with local people in the community they visit, by living with local people, working with them, and 
using the time when they are free from duties and obligations to interact with local residents.

Additionally, volunteer tourists are also argued to be motivated by a desire to gain different cultural experiences, which provide them with an opportunity for personal development, selfreflection and discovery (Carter, 2008; Simpson, 2005; Wearing, 2001). It is believed that they can only gain this experience outside their home country, ideally in a country that is physically and culturally different from their home (Jones, 2005). Moreover, Brown (2005) also points out that volunteer tourists are distinct from conventional volunteers in the sense that they seem to be driven by a desire to seek camaraderie, a sense of adventure, and a desire for exploration and novelty, motivations that are not as prominent among conventional volunteers.

Although some of the existing literature agrees that volunteer tourists are a type of tourist, they argue that volunteer tourists are different from other tourists in many ways. A number of factors are used to differentiate volunteer tourists from other tourists. Lepp's (2009) study indicates that volunteer tourists use the nature of their volunteer work to differentiate themselves from other tourists. Gray \& Campbell (2007) reveal that in the view of volunteer tourists and the host communities, four main criteria are used to differentiate the volunteer tourists from other tourists: (i) work; (ii) altruism; (iii) desire to learn; and (iv) local involvement.

Gray \& Campbell's (2007) study also adds that, in the opinion of volunteer tourists only, two further criteria differentiate them from other tourists: (i) a lesser need for amenities; and (ii) a longer stay. In the view of the host communities alone, further differentiation is found, including: (i) less money spent by the volunteer tourists; and (ii) lesser impact caused by them (Gray \& Campbell, 2007). Barbieri, Santos \& Katsube's (2012) study indicates that work, altruism, and learning are used by the host communities to distinguish between volunteer tourists and other tourists.

Brown (2005) argues that volunteer tourists are different from other tourists in terms of their greater sense of environmental responsibility and their preferred destinations, which tend to be remote and untouched, or poverty-stricken. In addition, Galley \& Clifton (2004) point out that volunteer tourists differ from other tourists in terms of the experience they are seeking. They note that the volunteer tourists tend to look for a higher level of interaction and engagement, as well as a physically and intellectually challenging experience. McGehee \& Andereck's (2009) study states that volunteer tourists require accommodation, food and transport in a more sustainable form than conventional tourists. It is evident from existing literature that the concept of volunteer tourists being different from other tourists is generally accepted.

\section{Attitudes of host communities towards volunteer tourists \\ Definitions of attitudes}

A number of scholars have attempted to define 'attitude' in order to give a basis for its understanding. Fishbein \& Ajzen (1975: 6) define an attitude as "a learned pre-disposition to respond in a consistently favo[u]rable or unfavo[u]rable manner with respect to a given object", whereas Fridgen (1991: 43) defines attitudes as "intellectual, emotional, and behavio[u]ral responses to events, things, and persons which people can learn over time."

There is some consensus here in that both definitions regard attitudes as being 'learned' predispositions that can 'direct' or 'influence' an individual to 'respond' in a certain way to given objects or events. Jafari (2000) argues that the term 'attitude' is synonymous with 'opinion', and therefore, they are used interchangeably in social science literature.

Ajzen \& Fishbein (1980) suggest that attitudes are connected with behaviour. They (1980: 62) explain this connection by using their Theory of Reasoned Action (TRA), which argues that, "a person's behavio[u]r is determined by his intention to perform the behavio[u]r and that this intention is, in turn, a function of his attitude towards the behavio[u]r and his subjective norm." In other words, the behaviours of people are believed to be influenced by their attitudes. 
Lepp (2007) also supports Ajzen \& Fishbein's (1980) argument by stating that the attitudes of host communities can lead to a certain reaction to the development of tourism in their communities, either positively or negatively. He (2007: 876) adds that "positive attitudes towards tourism could lead to pro-tourism behavio[u]r such as local participation in tourism development and the conservation of the resources on which tourism depends."

According to Ajzen \& Fishbein (1980: 19), attitudes are "complex systems comprising the person's beliefs about the object, his feelings towards the object, and his action tendencies with respect to the object." This implies that attitudes can be classified into three dimensions: (i) cognitive (beliefs, knowledge, perceptions); affective (the emotional aspect, expressed through feelings of like or dislike), and behavioural (the action component of attitudes that consists of the predisposition to act in a certain way).

The significance of understanding host communities' attitudes towards tourists and tourism development

It was mentioned earlier that host communities are in a position to provide either support of or hindrance of the development of tourism (Andereck \& McGehee, 2008; Ap, 1992). Examples of support provided by host communities include participation in the planning, development, and operation of tourist attractions, and extending hospitality to tourists (Ap, 1992; Lepp, 2007). On the other hand, host communities can also discourage tourism development by opposing it or exhibiting hostile behaviour towards tourists (Ap, 1992). Moreover, host communities are argued to be part of the tourism product (Taylor, 1995) and can make or break a positive experience for tourists (Knox, 1982).

Existing literature uniformly agrees that successful development of tourism in a community requires host communities to have positive attitudes towards tourists and to give their on-going support (Ambrož, 2008; Ap, 1992; Kuvan \& Akan, 2005). Murphy (1981:195) also suggests that host communities must be "willing partners" in tourism development. Furthermore, Lepp
(2007) argues that host communities' attitudes play an important role as an indicator of tourism's appropriateness. For example, positive attitudes may indicate that tourism has been developed appropriately and fits the local condition of the host communities. Therefore, to summarise, host communities' attitudes towards tourists and tourism development need to be considered by related tourism industry planners if they want on-going support from them (Andereck \& McGehee, 2008). There is also a suggestion that host communities' attitudes need to be constantly monitored, so that negative impacts and problems can be promptly rectified (Faulkner \& Tideswell, 1997; Jafari, 2001).

\section{Factors used in understanding host communities' attitudes}

In the past three decades, numerous studies have been conducted to understand the host communities' attitudes towards tourists and tourism development. Many of these attempted to identify factors that have an influence on host communities' attitudes. Cultural differences between tourists and host communities, community dependence on tourism's economic benefits and the impact of tourism are among these factors. Regarding cultural differences, Lepp (2007) argues that the cultural differences between tourists and host communities is found to significantly affect the host communities' attitudes, especially when the latter group is comprised of those who live in Eastern nations and the former are those from Western countries, because their cultural differences appear to be greater. He (2007: 879) also points out that some behaviours of Western tourists are seen as contrasting to the modest lifestyle of host communities, especially those in rural areas, and host communities' perception that tourists are "excessive consumers of sex, alcohol, food and natural resources" can trigger negative attitudes towards these tourists and tourism development.

Lepp's (2007) argument is echoed by Soontayatron's (2010) study on host communities' attitudes towards tourism impacts in Koh Samui. Soontayatron (2010) notes that there are huge differences in culture between Thai people and Western tourists, as the 
former are influenced by Buddha's teaching to reject a way of life dependent upon material possessions, while the latter group values capitalism. She (2010) argues that such cultural differences may lead to cultural conflict between tourists and host communities.

Regarding community dependence on tourism's economic benefits, Smith \& Krannich (1998) described host communities that are dependent on the economic benefits of tourism as 'tourism-hungry', and report that, despite the negative impacts of tourism, the residents in the tourism-hungry communities tend to have positive attitudes towards tourism development, as long as its economic benefits outweigh its negative impacts. This study is supported by the studies of Lepp (2007) and Soontayatron (2010), which report similar findings.

In terms of the impact of tourism, Lepp (2007) and Chandralal (2010) report that host communities' positive attitudes are primarily based on the perceived positive impacts of tourism, and although they are aware of its negative impacts, they still held favourable attitudes towards it as long as the positive impacts outweighed the negative. In line with this, Faulkner \& Tideswell (1997: 24) suggest that positive attitudes in host communities can also result from the phenomenon of an "altruistic surplus", which refers to 'an unselfish acceptance of certain costs in the interest of community-wide benefits.' In other words, altruistic surplus suggests that residents in the host community are likely to hold positive attitudes towards tourists and tourism development as long as their community as a whole enjoys positive impacts of tourism, despite the fact that they may personally experience some negative impacts.

Relevant literature on host communities' attitudes towards volunteer tourists

Currently, there are very few published studies on host communities' attitudes towards volunteer tourists and volunteer tourism. The well-known examples include McGehee \& Andereck's (2009) study of several communities in Tijuana, Mexico; Mclntosh \& Zahra's (2007) study of an indigenous Maori community in the North Island of New Zealand; Gray \& Campbell's (2007) study of Gandoca,
Costa Rica; Sin's (2010) study in Cambodia; and Guiney's (2012) study of orphanage tourism in Cambodia.

McGehee \& Andereck (2009) used social exchange theory to explain host communities' attitudes towards volunteer tourism. Their study suggests that perceived personal benefits from volunteer tourism have a strong influence on attitudes towards tourism development and would predict support for additional volunteer tourism. In other words, those residents who benefit the most from volunteer tourism are likely to have positive attitudes towards it and, in turn, are more supportive of volunteer tourism development. Conversely, residents who do not benefit to the same extent are more likely to perceive its negative impacts. The results of this study are consistent with their previous study in Arizona (see McGehee \& Andereck, 2004), which used a similar model but focused on mass tourism.

Moreover, Mclntosh \& Zahra's (2007) study indicates that host communities generally have favourable attitudes towards volunteer tourists and volunteer tourism in their community, and their positive attitude was primarily based on the conduct and behaviour of a previous group of volunteers who visited the community three years earlier, together with the trust that had been established with the volunteer tourism organisation. Their study also reports that these particular volunteer tourists are open, appreciate local culture, spend time with children, and do not behave as if they are from a culture superior to that of the local area; they are also perceived to bring about positive impacts for the community and the example set by the volunteer tourists was reported to be the biggest impact on the community. In addition, the same study reveals that some residents in the host community stated that volunteer tourists made the children proud to be Maori, because they showed interest in, and admiration for, Maori people and their culture.

Similarly, Sin's (2010) study reports that residents in the host community have positive attitudes towards volunteer tourists and they also saw the acts of the volunteer tourists as beneficial. This study also reveals that local residents are well aware of the good intentions 
of the volunteer tourists although they may have to deal with a language barrier.

The positive attitudes of residents in the host community towards volunteer tourists are also found in Guiney's (2012) study, which reveals that staff of the orphanage where volunteer tourism took place seethe volunteer tourists as a vital source of income for the orphanages, because they not only donate (both at the time of their visit and in the future), but also conduct fundraising, and sponsor projects, such as the construction of buildings. In addition, the same study found that the volunteer tourists are appreciated by the orphanage staff in terms of their roles in providing free education for both children and staff, especially the opportunity for the children to learn English from English native speakers. Moreover, the volunteer tourists are also seen as role models for the children for different career options.

Although the majority of the studies show that host communities generally have positive attitudes towards volunteer tourists, some studies report negative attitudes towards this type of tourist. For example, the study of Lo \& Lee (2011) points out that the great discrepancy between life in the host communities and that of the volunteer tourists may create negative feelings among the residents in the host communities, because they may feel inferior and frustrated when meeting volunteers from wealthier countries. In addition, the number of volunteer tourists can also cause some problems, such as insufficient food and resources if there are many volunteer tourists visiting at the same time. In line with this, the study of Simpson (2004) on the volunteer tourism experience of gap year students reveals that the great differences and inequality between the volunteer tourists and the residents in the host communities create simplistic boundaries between developed or northern countries and developing or southern countries, which in turn reinforces the notions of 'them' and 'us'.

\section{Methodology}

The primary aim of this study is to gain a rich and in-depth understanding of how local residents in Thai Muang sub-district who acted as the hosts perceive Western volunteer tourists. Given the nature of this study, an interpretive paradigm utilising a qualitative research approach, as opposed to a positivist paradigm, is considered most appropriate. This methodological approach is justified in terms of ontology, epistemology and methodology. Ontologically, this study posits that the hosts' attitudes towards volunteer tourists are socially constructed and 'based on interrelations and interactions' (Goodson \& Phillimore, 2004: 39) between the hosts, volunteer tourists and the environment in a specific context. In addition, it does not hold that the hosts are a homogenous group of people who share similar perspectives. In this sense, their attitudes appear to be diverse, based on the perception of each person. This assumption fits well with the interpretive paradigm.

Epistemologically, the interpretive paradigm holds that, in order to comprehend the social world, research should be conducted in a participatory and collaborative manner, with the researcher and the researched working as partners in the production of understanding and knowledge (Goodson \& Phillimore, 2004). Therefore, researchers are encouraged to obtain the emic perspective, which generally equips them to be able to enter and immerse themselves in the dynamic social setting being studied (Hollinshead, 2004) in order to interact with and gather the point of view described by the respondents (Jennings, 2001).

In contrast, positivists emphasise that the relationship between the researcher and the researched should be objective and value-free (Jennings, 2001). This is to ensure that there is a clear separation between the subjective biases of the researcher and the objects or events being studied (Cohen \& Crabtree, 2006). As mentioned above, this study holds that the hosts' attitudes are created through routine interrelations and interactions between hosts, volunteer tourists and the environment occurring in a study context, and so the epistemological assumption of an interpretive paradigm is deemed appropriate for this study.

This study employed the case study approach, using a combination of qualitative research methods as a means for the researcher to enter and become one of the actors in the 
volunteer tourism phenomenon at the study site. This approach also enabled the researcher to work together with the respondents in the production of knowledge of interest to this research

In terms of methodology, this study utilised a qualitative approach, rather than a quantitative approach because it does not seek to identify nor predict causal relationships. Instead, it aims to gain a holistic, rich and in-depth description of hosts' attitudes. In addition, it is believed that the statistical nature of quantitative research cannot sufficiently capture multiple realities of hosts' attitudes, nor enable the research's primary aim to be achieved.

This study employed an intrinsic case study approach, using the volunteer tourism programme offered by the Home and Life orphanage as the case. The orphanage is located in Thai Muang sub-district, Phang Nga province, Thailand. It is around 800 kilometres south of Bangkok. This area was one of those devastated by the Boxing Day tsunami in 2004.

The orphanage began to offer the volunteer tourism programme in 2009. More than $95 \%$ of the volunteer tourists are from Western countries including the UK, the Netherlands, Spain, Australia, and New Zealand. The opportunity for volunteer tourism at this orphanage is available all year round. Volunteer tourists typically spend around one to two weeks. They are required to work six hours a day and five days a week. Their main duties include taking care of the orphans, doing housework, and teaching English at a local school two days a week.

This study drew data from twenty Thai residents who acted as hosts of the volunteer tourists on working vacation at the Home and Life orphanage. These hosts consisted of staff members at the orphanage, teachers at the local school where the volunteer tourists went to teach English, and local residents who did construction work at the orphanage. The reason that the respondents were limited to these three groups is because volunteer tourism is still new in Thai Muang sub-district; therefore, there are only a few people who are in contact with the volunteer tourists or have an opinion about them. This limitation was identified during the pilot study when the researcher tried to interview other groups of local residents in Thai Muang sub-district, but found that they did not have rich information about the volunteer tourists to share with the researcher. Generally, they said that they liked to have these people in their community, but that was all.

The respondents were thirteen female and seven male, with ages ranging from twentythree to seventy-seven years. Twelve of them were married, five were single and the other three divorced. There was a wide range of educational backgrounds, from primary school (grade four) to Master's degree. In terms of professions, six were staff at the orphanage, seven were teachers, and the remaining seven were construction workers at the orphanage.

In keeping with the qualitative approach, this study used snowball sampling to identify and gain access to these respondents. The rationale for the using this technique is as follows: (i) the researcher was not familiar with the study site and therefore she had little idea about which individuals would possess the required characteristics; and (ii) Thai Muang sub-district is a small, close-knit sub-district where everyone knows each other. For these reasons, at the stage of designing the research process, the researcher believed that she could benefit from the established rapport with the manager of the orphanage, as well as take advantage of social networks and multiplier effects in which the manager might introduce others as additional respondents, and these respondents might in turn recommend other potential respondents to the researcher.

The criteria for selection were that subjects must be: (i) Thai citizens; (ii) eighteen years or older for ethical reasons; (iii) residents of Thai Muang sub-district for at least one year; and (iv) in roles or doing activities that involve contact with the volunteer tourists. As a result, twenty respondents were selected. This number was determined by the data saturation point; that is, when new categories or themes stopped emerging from the data. 
Before conducting the main study, the pilot study was undertaken at the Home and Life orphanage. During this period, the researcher stayed at the orphanage. The pilot study proved to be a very significant stage during the study process. It ensured that the data collection techniques were appropriately designed and would capture data relevant to the research questions. It also provided an opportunity for the researcher to practice interview techniques before conducting the main study. Moreover, the pilot study provided a clearer idea about the potential respondents for the main study. Before conducting the pilot study, the researcher could identify only two potential groups of local residents, which were the staff at the orphanage and the teachers at the local school. However, during the pilot study, another potential group of respondents was identified: local people who did construction work at the orphanage, as mentioned.

The main study was carried out between July and September 2011. A combination of semistructured interviews and participant observation was used to collect the data. The rationale for choosing semi-structured interviews as the main tool in collecting the data lies in their potential to enable a researcher to gather 'rich' data because it allows a researcher to clarify questions and probe the topics being investigated (Bebbie, 1990). Moreover, this type of interview corresponds to the interpretive paradigm, which is the framework of this study. However, the researcher was also aware that semi-structured interviews only allowed her to gain data on what respondents say, rather than on what they actually do. For this reason, participant observation was used to supplement the semistructured interviews. The data gained from participant observation can be used to triangulate with those gained from semistructured interviews.

All the interviews were video-recorded after obtaining permission via a consent form. All the respondents were ensured of the anonymity and confidentiality of their information by the use of pseudonyms in publication. The interviews were in the Thai language and took place at the orphanage and the local school where volunteer tourists work.

As for the participant observation, the researcher observed the behaviour of the respondents by using 'participant as observer' as categorised by Junker (1960), in which the respondents were aware of the researcher's identity and the researcher has regular interactions with the respondents. It was found that apart from observing the respondents, having informal conversations with them also helped the researcher to gain additional information not shared in interviews. The behaviour of the respondents and informal conversations with them were observed and recorded in the field notes, organised chronologically. The researcher was aware that in using participant observation, her own biases and misinterpretation of the data were risks. For this reason, triangulation and researcher reflexivity were employed to overcome these challenges.

The gathered data were analysed by thematic analysis technique. This analysis approach is defined by Braun \& Clarke (2006: 79) as "a method for identifying, analysing and reporting patterns (themes) within data." Specifically, the data analysis process followed six phases: (i) becoming familiar with the data; (ii) generating initial codes; (iii) searching for themes; (iv) reviewing themes; ( $v$ ) defining and naming themes; and (vi) producing the report. The data gathered from different techniques were crosschecked. The study not only sought convergence, but also differences or contradictions that occurred within the data. The reason for using thematic analysis lies in its accessibility and flexibility. As suggested by Braun \& Clarke (2006), thematic analysis provides an accessible and flexible method of qualitative data analysis because it is not attached to any particular theoretical or epistemological approaches, and thus it can be applied across different theoretical frameworks.

\section{Findings}

Data analysis reveals that the respondents generally held very positive attitudes towards the volunteer tourists. However, some respondents also expressed concerns about aspects of the volunteer tourists' behaviour and 
perceived under-performance. The important factors influencing positive attitudes and concerns of the respondents towards the volunteer tourists are discussed in turn. In addition, the views of the respondents on volunteer tourists in terms of whether they are tourists or non-tourists is also presented.

\section{Positive attitudes and relevant factors}

Respondents expressed a variety of feelings to show their positive attitude towards the volunteer tourists, which included: being impressed (e.g. by the volunteer tourists' conduct, performance and the benefits they had provided); being glad (e.g. to welcome the volunteer tourists to their community); being grateful (for the volunteer tourists' generosity, efforts, and dedication); being proud (of their own culture when the volunteer tourists showed an interest in it) and most importantly, feeling that having the volunteer tourists was necessary for them or their community.

The respondents' positive attitudes towards the volunteer tourists were primarily based on two main factors: (i) the conduct and the performance of the volunteer tourists; and (ii) the benefits the respondents perceived they had gained from them. These factors are shown in Figure 1 and are discussed as follows:

\section{The conduct and the performance of the volunteer tourists}

(i) Courteous conduct

The volunteer tourists were seen as being very friendly to the respondents, and being caring and kind to the children. These notions are exemplified in the following quotation:
Whenever we meet each other, they always smile and say 'hello' to me. Unlike other foreigners, they don't appear arrogant or have a frowning face to me and other teachers. This really makes me feel good and positive about them. (L12)

The volunteer tourists were commonly seen as being friendly, including smiling, greeting, not

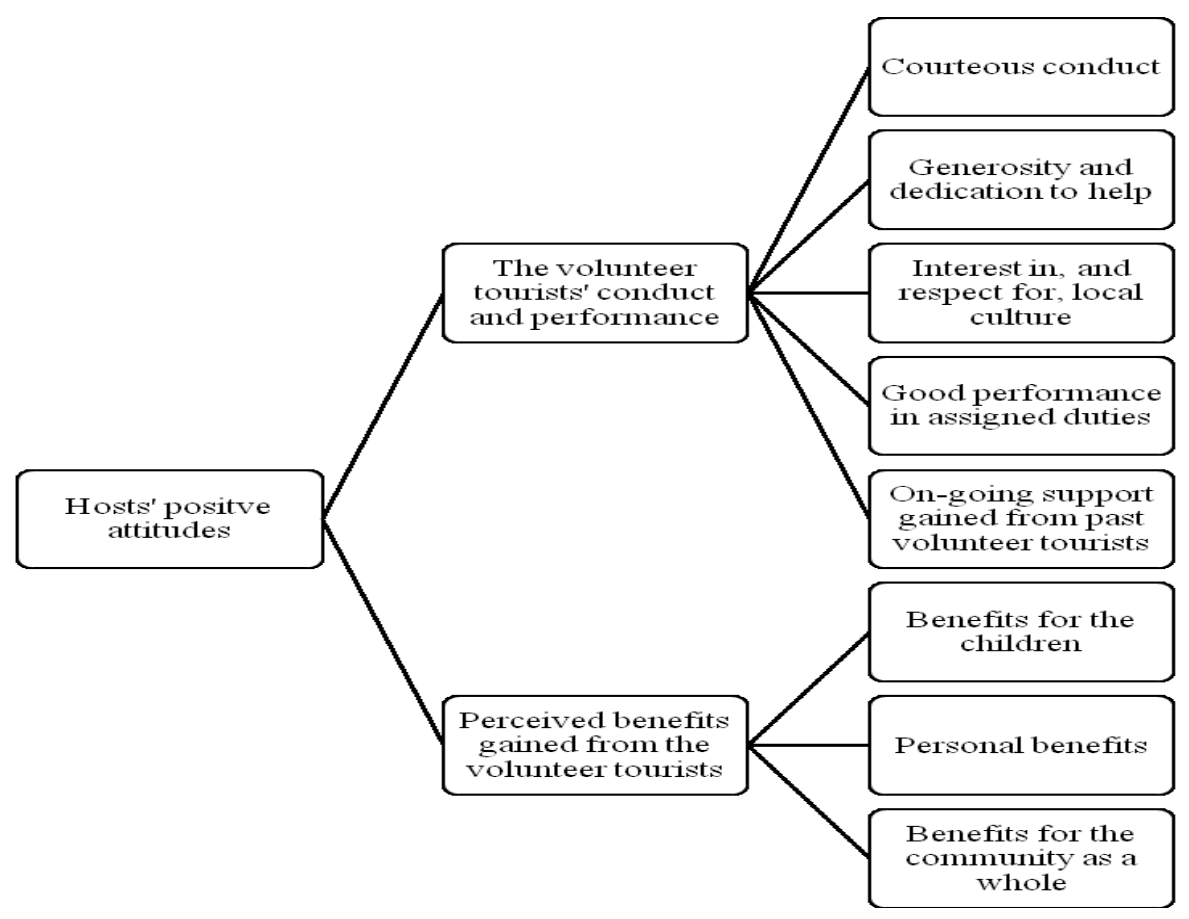

Figure 1. Factors influencing the hosts' positive attitudes 
being arrogant and being enthusiastic to talk with Thai people despite the language barrier. It is noteworthy that many respondents seemed to compare the volunteer tourists with other foreign tourists whom they had met before. In their view, the latter appeared to be unfriendly and arrogant. Therefore, they were quite surprised to find that these volunteer tourists were different.

\section{(ii) Generosity and dedication to help}

The volunteer tourists were also perceived by the respondents as being generous and dedicated to providing help. This conduct of the volunteer tourists was not only expressed in the form of donations of money and items to the children, but also in dedication of time and labour in order to do goodwill activities for the host community without seeking anything in return.

It was also found that the respondents were grateful for the generosity and dedication of the volunteer tourists. A sense of gratitude is an essential element in Buddhist Thai society. Thai people are taught to be grateful to everyone and everything that they believe has done good things for them and they feel an obligation to repay or return favours to those people whenever possible. Therefore, it is not surprising that some respondents were concerned about their obligation to return favours to the volunteer tourists within their ability, such as providing refreshments and teaching materials for them, and being generous to them. Moreover, the orphanage staff showed their gratitude to the volunteer tourists by giving a certificate to them.

\section{(iii) Interest in, and respect for, local culture}

Many respondents were very glad to learn that the volunteer tourists had an interest in, and showed respect for, Thai culture. They revealed that the volunteer tourists were excited to experience Thai culture and wanted to learn about it; some volunteer tourists also tried to practice some aspects of Thai culture, such as greeting others in the Thai style, speaking Thai, and dressing in Thai traditional costume. Moreover, the volunteer tourists' interest in Thai culture also made them feel that these volunteer tourists shared their interest in the things that they regard as significant for their society, as well as making them proud of their own culture.

The aspect of religious belief is another important issue that emerges from the interviews. In Thailand, it has been common to see Western Christian missionaries trying to disseminate their religious beliefs to Thai people. Some Thai people are against these missionaries and this feeling is also shared by many respondents. However, the respondents had realised that the volunteer tourists did not come for this purpose, which made them feel positive about the volunteer tourists. Moreover, the respondents stated that the volunteer tourists were respectful to the religious beliefs of Thai people. Some respondents stated that the volunteer tourists showed this by joining in activities relating to Buddhist beliefs, such as praying and practicing meditation.

\section{(iv) Good performance in assigned duties}

The volunteer tourists' performance in the assigned duties was largely complimented by the orphanage staff and the teachers who had witnessed the performance of the volunteer tourists most closely, compared to other respondents. Moreover, they were the groups of respondents who appeared to benefit most from the activities done by the volunteer tourists.

The volunteer tourists were complimented as being self-disciplined in terms of punctuality and working in an orderly fashion, always put forth their best efforts and working hard on their assigned jobs. As stated by L04, who was a teacher:

These volunteers are always punctual...When they tell the students to work on some things, they make sure that the students work [in an] orderly [fashion]. Suppose they use the paper for some activities in the class; when they finish, they always make sure that the classroom was cleaned and in an orderly state such as no paper is left under the tables.

(v) On-going support gained from past volunteer tourists

This factor was only mentioned by the orphanage staff. This is because they are 
closer to the volunteer tourists, compared to other groups of respondents. It is evident that most of the staff at the orphanage and the volunteer tourists had established a good relationship with each other during the time that the latter group stayed and worked at the orphanage. Such relationships remained strong after the volunteer tourists left the orphanage.

The staff and the children at the orphanage received on-going support from many of the past volunteer tourists in four major forms: donations of objects and money; fundraising activities on behalf of the orphanage; sponsoring orphanage projects; and promoting the volunteer tourism programme at the orphanage to other people.

\section{The perceived benefits gained from the volunteer tourists}

The second factor that played an important role in influencing the respondents' positive attitudes towards the volunteer tourists was the perceived benefits they had gained from the volunteer tourists. These perceived benefits can be categorised as follows: (i) benefits for the children; (ii) personal benefits; and (iii) benefits for the community as a whole. Each of these perceived benefits is discussed in turn.

\section{(i) Benefits for the children}

The word 'children' covers both the children at the orphanage and the students at the local school. When the respondents spoke about the benefits they believed they had received from the volunteer tourists, they primarily mentioned those relating to the children. This shows that the respondents really care about the children in the community. Therefore, when they perceived that the children had benefited from the presence, conduct and performance of the volunteer tourists, they did not hesitate to portray positive attitudes towards them.

The benefits which the children had gained from the volunteer tourists can be categorised into six main groups: donations; an opportunity to study English with native speakers; familiarity with Western people; good role models; an opportunity to develop their skills and abilities; and being happier as a result of the care given by the volunteer tourists.
In terms of monetary donations, the children at the orphanage had been receiving monetary donations from the volunteer tourists since the orphanage first started offering the volunteer tourism programme. This money had been used for their education and living expenses, which include food, clothes, books etc. In addition, they had received donations in the form of items such as stationery, books, medicines, clothes, computers and toys etc. The items donated were also extended to the students at the school, normally in the form of stationery, books and toys.

The second benefit that the children gained from the volunteer tourists was an opportunity to study English with English native speakers, or Western people whose English is good. All of the respondents felt that this was the most significant benefit for the children and it was also found to be the most important factor influencing their positive attitudes towards the volunteer tourists. This is because they were aware that English is the most widely-used language around the world. In addition, there are many foreign visitors who come to Thailand, either for travelling, leisure or business purposes. For these reasons, the ability to communicate in English is viewed as being important if one would like to earn good money in the future. People who have good English are believed to have more opportunities than those who do not.

The respondents stated that the volunteer tourists had been helping to improve the children's English communication ability significantly, and the children's English was better than that of other children at the same age. In Thai Muang sub-district, there are very few Western people visiting because it is not a famous tourist attraction and most of these Westerners were not as accessible as the volunteer tourists. Therefore, the volunteer tourists were seen as the only source of firsthand experience available for the children to learn English.

Apart from the English language, the volunteer tourists also provided an opportunity for the children to develop other skills and abilities by either raising funds for skill-development projects, or using their own expertise or skills to 
teach the children, such as playing tennis, or arranging for a trainer of other sport for the children.

The fourth benefit which the children had gained from the volunteer tourists was an opportunity to become familiar with Western people, which, in turn, made them more confident when they met foreigners. The confidence of these children was seen to be different from other Thai children, who are shy or scared of Western people. Moreover, the respondents also perceived that being familiar with Western people provided the children with an opportunity to learn about Western culture, such as some aspects of social etiquette and tips about daily life (e.g. how to greet people in a Western style, what to say when someone sneezes etc.), which is seen as being beneficial for them if they choose to work in the hotel or other service industries.

Additionally, the volunteer tourists were seen as being good people who could serve as good models for the children in many ways, such as helping others without seeking anything in return, generosity, and protecting the environment. The volunteer tourists could also inspire the children to study at a high level. Some residents also indicated that the volunteer tourists inspired the children to realise the significance of their own community because they had witnessed that the volunteer tourists had come to do good things for their community, so they, as the members of the community, should also do good things for their own community when they grow up.

Finally, the respondents believed that the children were happier and 'warmer' from the care given by the volunteer tourists. They realised that the children at the orphanage generally encountered emotional and psychological privations more than other children, as they could not live with their own parents. Therefore, they felt that the volunteer tourists, whom they think are good people, could help fulfil these needs. They thought that the volunteer tourists came with good hearts, and good feelings towards these children, so that the love and care given by them had made the children feel warmer and happier. These notions are clearly reflected in L06's statement:
As we know that most of the children at this orphanage don't have parents, so, when there are good people[the volunteer tourists] coming to help take care of them ... They feel mentally warmer...they just want to hold their hands and hug them. This is enough for them to be happy.

\section{(ii) Personal benefits}

It was found that the personal benefits were not considered as important as the benefits for the children. Some respondents viewed the benefits they gained from the volunteer tourists as side benefits, whereas some respondents did not mention these benefits at all until prompted. An explanation for this could be that the respondents gave priority to the children, or that they were well aware that the focus of the volunteer tourists was the well-being of the children, rather than that of the adults. The personal benefits that the respondents had received from the volunteer tourists include: having more friends; relief from their own responsibilities; an opportunity to learn/practice English; and an opportunity to learn new skills.

As mentioned earlier, the orphanage staff regarded the volunteer tourists as their friends, both during and after their stay. Therefore, it is not a surprise to find that 'having more friends' was commonly mentioned as a personal benefit gained from the volunteer tourists by most of the orphanage staff.

The second personal benefit respondents received from the volunteer tourists was being relieved of responsibility. This was overwhelmingly mentioned by the teachers, because every teacher had his/her own class for which he/she was responsible and had to teach almost every subject, including English, which they were not good at. Therefore, when their responsibility for teaching English was relieved by the volunteer tourists, they were very happy because they had more time to do other tasks, such as correcting the students' homework or going to the library. Moreover, as they realised that they were not good at teaching English language, they thought that the students would benefit a lot more from studying English with the volunteer tourists. Additionally, this type of benefit is also mentioned by the orphanage staff and the 
construction men, who had been relieved by the volunteer tourists of their responsibilities.

Thirdly, the respondents also had a good opportunity to learn and practice their English with the volunteer tourists. Having to work regularly with the volunteer tourists forced the respondents to speak English with them, which consequently helped boost their confidence in speaking English with foreigners.

Additionally, having an opportunity to learn new skills from the volunteer tourists was also cited as another important benefit that the respondents gained from the volunteer tourists. Since the volunteer tourists came from different backgrounds, they had acquired a variety of skills and expertise to share with the respondents. For example, some volunteer tourists had a good knowledge of looking after children; others were nurses or doctors who could share their knowledge of first aid; and others had skill in decorating and cooking.

\section{(iii) Benefits for the community}

Having the volunteer tourists in the community was also perceived as beneficial for the community as a whole. These benefits include: promoting tourism in the community; gaining more income; and providing assistance in various community services.

Specifically, the respondents stated that the volunteer tourists helped promote the tourist attractions of Thai Muang sub-district to their friends and families by producing good word-ofmouth information about the area and actively recommending visiting the area to others.

Moreover, some respondents pointed out that the volunteer tourists generated extra income for local people in the community by spending money buying fruit, food and other things from them. In addition, volunteer tourists helped in various kinds of community services, such as doing maintenance work for the temples and the local medical stations, and helping the police to communicate with other foreigners if they had problems.

\section{The respondents' issues of concern}

Some respondents also expressed their concerns about some of the volunteer tourists' behaviour and perceived under-performance. Issues of concern relating to the volunteer tourists' behaviour included inappropriate dress and showing affection in public. Underperformance referred to tasks such as taking care of the children, and doing housework. These factors are shown in Figure 2.

\section{The volunteer tourists' behaviour}

The behaviour of the volunteer tourists that was perceived by the respondents as inappropriate involves the way they dress and show affection in public (i.e. kissing and hugging). Regarding the issue of inappropriate dress, this originated mainly from the female volunteer tourists who

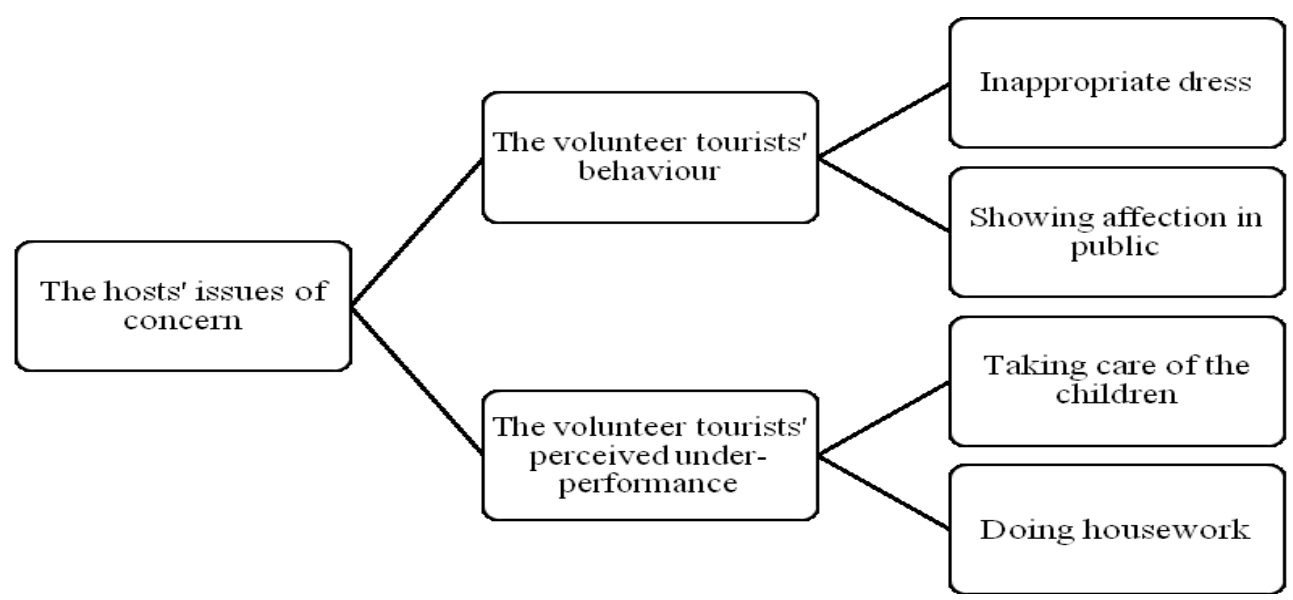

Figure 2. The hosts' issues of concern 
dressed in such a way that too much skin was shown to be considered appropriate in Thai culture. Thai people generally dress in such a way as to ensure that most of their skin is covered. This was the most cited concern expressed by the respondents. They were very worried about this issue, because the volunteer tourists had to spend most of their time with the children and they also took on the role of teaching; therefore, they were expected to be role models for the children in every way, including how to dress. Furthermore, they also had to work with construction men sometimes, so it was not appropriate for women to wear sexy clothes. As L07 said, "Some of them [the volunteer tourists] wear a sexy strappy vest top with a low neckline ...I would like them to dress properly because they are a teacher as well."

As for showing affection in the public, many volunteer tourists came as part of a couple and some of them showed affection in public, such as hugging or kissing each other openly. In addition, the majority were teenage couples who were not married and slept together in the same room. This conduct was considered inappropriate in Thai culture. Thai people are very reserved; they believe that showing affection within a couple must be done only in private, and only married couples can sleep together in the same room. The respondents thought that this conduct might set a bad example for the children.

\section{The volunteer tourists' performance}

The under-performance of the volunteer tourists involves their performance in taking care of the children, doing housework and teaching English. Some orphanage staff stated that the volunteer tourists, especially those who were teenagers, could not perform the assigned tasks properly. For example, they did not actually help the children when taking a bath but just watched while they were taking a bath by themselves; they did only what they were assigned to do without using their initiative; they did not know how to perform some specific tasks properly, such as ironing or hanging the clothes; and they allowed students to walk freely in class without asking permission. However, the respondents did not accuse the volunteer tourists of being irresponsible; on the contrary, they thought that this occurred because the volunteer tourists had never done these tasks before and they might need time to adjust, as well as cultural differences.

It is noticeable that these concerns were not exactly negative attitudes, because the respondents thought these issues could be easily be prevented and/or rectified. In fact, at the time of conducting the main study, some of these issues of concern had already been prevented and/or corrected to the satisfaction of the respondents (e.g. inappropriate dressing and showing affection in public). However, since the respondents still mentioned it, this might imply that they were still concerned and would not be happy to find that future volunteer tourists had such behaviour and/or performance issues.

\section{Volunteer tourists: tourists or not}

There were mixed views regarding the perception of respondents in terms of whether volunteer tourists are 'true' tourists. Some respondents viewed the volunteer tourists as being non-tourists, whereas some perceived them as a special type of tourist. The former group generally used the word 'tourists' as referring to mass tourists who visit the tourist attractions for only self-serving purposes, and do nothing to help the community; therefore, they felt reluctant to call them tourists when they had come to provide assistance to their community. The latter group of respondents were aware that volunteer tourists also went to visit other places for leisure purposes like other tourists, but they were seen as being different to other tourists, especially mass tourists, in that they spent their free time helping host communities or 'giving back' to the place where they visit.

Specifically, volunteer tourists were viewed as being different to other tourists in five main aspects: (i) they spend part of the vacation helping/working for the place they visit without seeking anything in return; (ii) they are more eager to learn about local culture and to have close interaction and involvement with local people; (iii) they require only basic accommodation and food; (iv) they normally spend less money; and (v) they generate more benefits for the host community. 


\section{Discussion}

Thai hosts' attitudes towards the volunteer tourists as described in this study include all three dimensions of cognitive, affective, and behavioural, as suggested by Ajzen \& Fishbein (1980). In terms of the cognitive dimension, the hosts' attitudes showed their beliefs, knowledge, and perceptions relating to the volunteer tourists. As for the affective dimension, a variety of feelings were displayed. Lastly, in terms of the behavioural dimension, the hosts' attitudes were expressed through the friendliness and hospitality they showed the volunteer tourists.

The findings of this study support the argument made by Fredline \& Faulkner (2003) and McGehee \& Andereck (2004), who state that residents in the host community are heterogeneous groups of people who possess diverse characteristics, and are thereby likely to have variation in their attitudes towards tourists. Although generally all the respondents expressed positive attitudes towards the volunteer tourists, the expression of their feelings and opinions about the volunteer tourists did vary in some specific details.

Perhaps one of the most interesting findings of this study was that, generally, the respondents willingly accepted the superiority of the Western volunteer tourists without having any negative feelings regarding their own inferiority. This finding is inconsistent with Lo \& Lee (2011), who argue that the great discrepancy between the life of the residents in the host community and that of volunteer tourists from Hong Kong, who appear to be more privileged and more wealthy, might have created negative feelings among local residents, causing them to feel inferior and frustrated. On the contrary, the current study found that many respondents were well aware of the superior status of the volunteer tourists, which was reflected in statements such as "these people come from richer and more developed countries than ours"; "when they come to Thailand, they bring with them civilisation and modernity to share with us"; "they have more opportunities than us"; and "they come from a more civilised country."
Moreover, the respondents viewed the Western volunteer tourists as being better in terms of working, compared to Thai people. For example, they were seen as role models for both adults and children in terms of selfdiscipline (e.g. punctuality and working in an orderly fashion) and always working hard. This knowledge did not make the respondents frustrated; on the contrary, they felt grateful to the volunteer tourists that these people wanted to share their privileges with them or to help lessen the gap by helping the children, who were the future of the community, by providing education, donating money and teaching English.

One possible explanation for this phenomenon was that the Thai residents were satisfied with who they are and what they already have (although they did not reject any development which could make they lives better, as long as that development was not contradictory to their ways of living). Moreover, this study is in agreement with Kislenko (2004), who points out that Thailand has never been colonised by Western nations; therefore, Thai people do not suffer emotional 'hang-ups' of having been colonised, and are free from anti-Western feeling.

Although the respondents accepted the superiority of the Western volunteer tourists and believed that they could benefit from such superiority, they had concerns about cultural difference between them and the tourists, especially in terms of the degree of conservativeness. It is evident that the hosts expected the tourists to respect and follow the practices of local culture. This finding supports the argument made by Lepp (2007), who states that cultural difference between tourists and host communities is found to significantly affect the attitudes of the latter, especially when the former are Western people and the latter group are Eastern residents. $\mathrm{He}$ (2007) also said that some of the behaviour of the Western tourists was seen as being contradictory to the modest lifestyle of the host communities, especially those in rural areas.

The overall findings of this study are in line with the studies of Barbieri et al. (2012), Mclntosh \& Zahra (2007), and Sin (2010). It was found that 
the hosts in Thai Muang sub-district generally had favourable attitudes towards the volunteer tourists. However, in terms of the factors influencing their positive attitudes, the findings of the study are inconsistent with those of McIntosh \& Zahra (2007).

According to McIntosh \& Zahra's (2007) study, positive attitudes in a host community are primarily based on two factors: the conduct and behaviour of previous groups of volunteer tourists; and the trust the host community has established with the volunteer tourism organisation. In this study, however, although the conduct and performance of the volunteer tourists was mentioned as a significant cause of hosts' positive attitudes, it was not mentioned as relating to only the previous group of volunteer tourists, but rather to both the previous group and the current group. Moreover, the trust established between the host community and the volunteer tourism organisation, as suggested by Mclntosh \& Zahra (2007), was not identified as a factor influencing the hosts' attitudes in this study.

A possible explanation for this difference in the findings could be that, in the view of the respondents, the good conduct and performance of the volunteer tourists and the benefits they gained from these tourists were only associated with the volunteer tourists themselves, not with the volunteer tourism organisers.

In the context of orphan volunteer tourism, this study found that the benefits gained from the volunteer tourists in terms of an opportunity for the children to study English with English native speakers was perceived as invaluable and strongly influenced the hosts' positive attitudes. A similar finding is reported in the study of Guiney (2012), who explored orphan volunteer tourism in Cambodia, and Sin (2010), who studied host community perception in Cambodia.

However, this finding is in contrast with other studies (e.g. Lepp, 2007; Smith \& Krannich, 1998; and Soontayatron, 2010) that examine host communities' attitudes towards leisure tourists, and report that the perceived economic benefit gained from tourists is the primary factor influencing the positive attitudes of host communities. Although the economic benefits gained from the volunteer tourists were mentioned by some respondents in this study, such as in terms of gaining extra income, they only served as side benefits gained from the volunteer tourists.

A possible explanation for this difference may lie in the fact that, firstly, the local people in Thai Muang sub-district did not depend on tourism's economic benefits, but on fishing and the cultivation of crops. Unlike Khao Lak, which is located around thirty kilometres from Thai Muang sub-district and is well-known as a tourist resort, Thai Muang has never been known as a tourist destination, but serves only as a passageway between well-known tourist attractions in Phang Nga province, such as Khoa Lak and Phuket province.

Secondly, the volunteer tourists were viewed as different to mass tourists who always spend a lot of money at the places they visit. They were perceived as either non-tourists or special kinds of tourists who generally spend less money; therefore, they were not expected to generate economic benefits for the community, especially in terms of a main source of income or employment. In addition, the hosts were also aware that most of the volunteer tourists who participated in the volunteer tourism at the orphanage were teenagers, who were perceived as having little money to spend on their vacation.

The fact that the respondents had overall positive attitudes towards the volunteer tourists, despite having some concerns, supports the concept of 'altruistic surplus' suggested by Faulkner \& Tideswell (1997). To reiterate briefly, they suggest that host communities are likely to hold positive attitudes towards tourism as long as their community as a whole still experiences positive impacts of tourism, even if they personally experience some negative impacts of tourism.

\section{Conclusion and implication}

The findings of this study contribute to the literature on volunteer tourism, especially in terms of the hosts' attitudes towards volunteer tourists. The contribution can be contextualised 
into two main aspects: (i) contributing to the emerging debate on the potential of volunteer tourism in reinforcing inequality between Western volunteer tourists and host communities of a developing country; and (ii) analysing the role of children in influencing the attitudes of the residents in the host community towards volunteer tourists.

First, the findings of this study challenge the idea that volunteer tourism may reinforce inequality between developed and developing nations as well as deepen dichotomies of 'them' and 'us', instead of promoting true crosscultural understanding between volunteer tourists and host communities, as argued by several scholars (Barkham, 2006; Brown \& Hall, 2008; Simpson, 2004). The findings suggest that the hosts were already aware of the economic and educational inequalities existing between them and Western volunteer tourists, and that interaction with volunteer tourists did not reinforce this inequality or make it appear larger. On the contrary, the hosts felt that volunteer tourism potentially lessened this gap because volunteer tourism not only served as an effective mean of transferring wealth and knowledge but also promoted cross-cultural understanding. Whilst cultural differences did occur and caused issues of concern among some members of the community, these differences were not new to them. However, there was concern about how these issues may impact upon children who have less knowledge and experience of cultural difference.

Secondly, this study argues that the perceived benefits that volunteer tourists provided for the children have a significant role in forming hosts' attitudes. Among these benefits, an opportunity to study English with native speakers was perceived as the strongest factor. As for their concerns, these focused on the well-being of the children because they were afraid that some of the behaviour of the volunteer tourists, such as the way they dress and show affection in public, might be a bad example for the children.

In terms of practical implications, this study provides insight for volunteer tourism organisations and other related stakeholders such as governments and local authorities about the perceptions of host community in a developing country towards Western volunteer tourists. This insight can help these organisations in developing volunteer tourism programmes that meet the interests and needs of host communities.

\section{Limitations and directions for future research}

The limitations of this study are associated with the nature of its research methodology. This research is underpinned by an interpretive paradigm utilising qualitative research methods, and is based on only one case study and a small number of respondents derived from non-probability sampling; therefore, the findings are unique and cannot be generalised to other groups of residents in other host communities.

In terms of direction for future research, this study suggests that more work on the role of volunteer tourism in alleviating poverty in the host community is needed. One of the key findings that emerged from this study is that some residents in Thai Muang sub-district had enjoyed economic benefits from the volunteer tourists in the form of job opportunities and generating income. Although the scope of this study does not cover the role of volunteer tourism in terms of economic enhancement or poverty reduction, it does support anecdotal conclusions drawn elsewhere (e.g. Gray \& Campbell, 2007; McGehee\& Andereck, 2009; Morgan, 2010; Wearing, 2001), which claim that volunteer tourism can enhance local economic development and alleviate poverty in the host community. To date, it is still not yet fully understood as to what extent volunteer tourism can alleviate poverty and how it can be used for this purpose efficiently, because this topic is still under-researched. For this reason, a study of the role of volunteer tourism in poverty reduction is recommended, especially in a developing country like Thailand where the majority of people are still living in poverty and volunteer tourism is increasing.

\section{References}

Ackerberg, I., P. Prapasawudi (2009) An analysis of volunteer tourism using the repertory grid technique (Unpublished master's degree dissertation). 
University of Gothenburg. Göteborg, Sweden.

Ajzen, I., M. Fishbein (1980) Understanding attitudes and predicting social behaviour. Englewood Cliffs, NJ: Prentice-Hall.

Alexander, Z. (2012) International volunteer tourism in South Africa: an investigation into the impact on the tourist. Journal of Hospitality Marketing and Management 21(7), 779-799.

Ambrož, M. (2008) Attitudes of Local Residents towards the Development of Tourism in Slovenia: The Case of the Primorska, Dolenjska, Gorenjska and Ljubljana regions. Anthropological Notebooks 14(1), 63-79.

Andereck, K.L., N.G. McGehee (2008). The attitudes of community residents towards tourism. In Stephen, M., R.N. Moisey (eds.) (2008) Tourism, recreation, and sustainability: linking culture and the environment $\left(2^{\text {nd }}\right.$ ed.). Wallingford: CAB International, 236259.

Ap, J. (1992) Residents' perceptions on tourism impacts. Annals of Tourism Research 19(4), 665-690.

Barbieri, C., C.A. Santos, Y. Katsube (2012) Volunteer tourism: on-the-ground observations from Rwanda. Tourism Management 33(3), 509-516.

Barkham, P. (2006) Are these the new colonialists? The Guardian. URL: http://www.guardian.co.uk/society/2006/ aug/18/internationalaidanddevelopment .education (Accessed on 14.08.2014).

Bebbie, E.(1990) Survey research methods. Belmont, CA: Wadsworth.

Braun, V., V. Clarke (2006) Using thematic analysis in psychology. Qualitative Research in Psychology 3(2), 77-101.

Broad, S.(2003) Living the Thai life - a case study of volunteer tourism at the Gibbon Rehabilitation project, Thailand. Tourism Recreation Research 28(3), 63-72.

Brown, F., D. Hall (2008) Tourism and development in the global south: the issues. Third World Quarterly 29(5), 839-849.

Brown, S. (2005) Travelling with a purpose: understanding the motives and benefits of volunteer vacationers. Current Issues in Tourism 8(6), 479-496.

Brown, S., A.M. Morrison (2003) Expanding volunteer vacation participation: an exploratory study on the mini-mission concept. Tourism Recreation Research 28(3), 73-82.

Callanan, M., S. Thomas (2005) Volunteer tourism- deconstructing volunteer activities within a dynamic environment. In Novelli, M. (ed.) (2005) Niche tourism contemporary issues, trends and cases. Oxford: Elsevier/Butterworth-Heinemann, 183200.

Carter, K.A. (2008) Volunteer tourism: An exploration of the perceptions and experiences of volunteer tourists and the role of authenticity in those experiences (Unpublished Master's degree dissertation). Lincoln University, New Zealand.

Chandralal, K.P.L. (2010) Impacts of tourism and community attitude towards tourism: a case study in Sri Lanka. South Asian Journal of Tourism and Heritage 3(2), 41-49.

Chen, L., J.S. Chen (2011) The motivations and expectations of international volunteer tourists: A case study of "Chinese Village Traditions"'. Tourism Management 32(2), 435-442.

Cohen, D., B. Crabtree (2006) The positivist paradigm: Qualitative research guidelines project. URL: http://www.qualres.org/ HomePosi3515.html (Accessed on 4.09.2013).

Corti, I.N., P.N. Marola, M.B. Castro (2010) Social inclusion and local development through European voluntourism: A case study of the project realised in a neighborhood of Morocco. American Journal of Economics and Business Administration 2(3), 221-231.

Faulkner, B., C. Tideswell (1997) A Framework for Monitoring Community Impacts of Tourism. Journal of Sustainable Tourism 5(1), 3-28.

Fishbein, M., I. Ajzen (1975) Belief, attitude, intention, and behaviour: An introduction to theory and research. Reading, MA: Addison-Wesley. 
Fredline, E., B. Faulkner (2003) Host community reactions: a cluster analysis. In Fredline, L., L. Jago, C. Cooper (eds.) (2003) Progressing tourism research. Clevedon: Channel View Publications, 93-113.

Fridgen, J. (1991) Dimensions of tourism. East Lansing, MI: American Hotel and Motel Association Educational Institute.

Galley, G., J. Clifton (2004) The motivational and demographic characteristics of research ecotourists: Operation Wallacea volunteers in south-east Sulawesi, Indonesia. Journal of Ecotourism 3, 69-82.

Goodson, L., J. Phillimore (2004) The inquiry paradigm in qualitative tourism research. In Phillimore, J., L. Goodman (eds.) (2004) Qualitative research in tourism: Ontologies, epistemologies and methodologies. London: Routledge, 30-45.

Gray, N.J., L.M. Campbell (2007) A decommodified experience? exploring aesthetic, economic and ethical values for volunteer ecotourism in Costa Rica. Journal of Sustainable Tourism 15(5), 463-482.

Guiney, T. (2012) 'Orphanage tourism' in Cambodia: when residential care centres become tourist attractions. Pacific News 38, 9-14.

Guttentag, D.A. (2009) The possible negative impacts of volunteer tourism. International Journal of Tourism Research 11(6), 537-551.

Harlow, S., G. Pomfret (2007) Evolving environmental tourism experiences in Zambia. Journal of Ecotourism 6(3), 184-209.

Hollinshead, K. (2004) A primer in ontological craft: The creative capture of people and places and places through qualitative research. In Phillimore, J., L. Goodman (eds.) (2004) Qualitative research in tourism: Ontologies, epistemologies and methodologies. London: Routledge, 63-82.

Jafari, J. (2000) Encyclopedia of tourism. London: Routledge.

Jafari, J. (2001) The scientification of tourism. In Valene, S., B. Maryann (eds.) (2001) Hosts and Guests Revisited: Tourism
Issues of the $21^{\text {st }}$ Century. Elmsford, NY.: Cognizant Communication Corporation, 28-41.

Jennings, G.(2001) Tourism research. Milton, Australia: John Wiley\& Sons.

Jones, A. (2005) Assessing international youth service programmes in two low income countries. Voluntary Action: The Journal of the Institute for Volunteering Research 7(2), 87-100.

Junker, B.H. (1960) Fieldwork: An introduction to the social sciences. Chicago: University of Chicago Press.

Kepher-Gona, J. (2008) Travellers' philanthropy. Ecotourism Kenya 20, 112.

Kislenko, A. (2004) Culture and customs of Thailand. London: Greenwood Press.

Knox, J.M. (1982) Resident-visitor interaction: A review of the literature and general policy alternatives. In Rajotte, F. (ed.) (1982) The impact of tourism development in the Pacific. Ontario, Canada: Environmental Resources Study Programme, Trent University, 76-107.

Kuvan, Y., P. Akan (2005) Residents' attitudes toward general and forest-related impacts of tourism: The case of Belek, Antalya. Tourism Management 26(5), 691-706.

Lepp, A. (2007) Residents' attitudes towards tourism in Bigodi village, Uganda. Tourism Management 28(3), 876-885.

Lepp, A. (2009) Leisure and obligation: an investigation of volunteer tourists' experience at Kenya's Taita Discovery Center. Journal of Leisure Research 41(2), 253-260.

Lo, A., C. Lee (2011) Motivations and perceived value of volunteer tourists from Hong Kong. Tourism Management 32(2), 326-334.

Lyons, K. (2003) Ambiguities in volunteer tourism: A case study of Australians participating in a $\mathrm{J}-1$ Visitor Exchange Program. Tourism Recreation Research 28(3), 5-13.

McGehee, N.G., K.L. Andereck (2004) Factors predicting rural residents' support of tourism. Journal of Travel Research 43(2), 131-140. 
McGehee, N.G., K.L. Andereck (2009) Volunteer tourism and the "voluntoured": the case of Tijuana, Mexico. Journal of Sustainable Tourism 17(1), 39-51.

McGehee, N.G., C. Santos (2005) Social change, discourse and volunteer tourism. Annals of Tourism Research 32(3), 760-779.

Mclntosh, A.J., A. Zahra (2007) A cultural encounter through volunteer tourism: towards the ideals of sustainable tourism? Journal of Sustainable Tourism, 15(5), 541-556.

Morgan, J. (2010) Volunteer tourism: What are the benefits for international development? The VolunTourist Newsletter 6(2). URL: http://www.voluntourism.org/newsstudyandresearch62.htm (Accessed on 15.07.2014)

Murphy, P.E. (1981) Community attitudes to tourism: A comparative analysis. International Journal of Tourism Management 3,189-195.

Mustonen, P. (2006) Volunteer tourism: Postmodern pilgrimage? Journal of Tourism and Cultural Change 3(3), 160-177.

Nestora, A., P. Yeung, H. Calderon (2009) Volunteer travel insights 2009. Bradt travel guides, Lasso communications. GeckoGo.

URL:

http://www.geckogo.com/volunteer/rep ort2009 (Accessed on 25.08.2014)

Ooi, N., J.H. Laing (2010) Backpacker tourism: sustainable and purposeful? investigating the overlap between backpacker tourism and volunteer tourism motivations. Journal of Sustainable Tourism 18(2), 191-206.

Palacios, C.M. (2010) Volunteer tourism, development and education in a postcolonial world: conceiving global connections beyond aid. Journal of Sustainable Tourism 18(7), 861-878.

Raymond, E. (2007) Making a difference?: Good practice in volunteer tourism (Unpublished Master's degree dissertation). University of Otago, New Zealand.

Raymond, E.M., C.M. Hall (2008) The development of cross-cultural (mis)understanding through volunteer tourism. Journal of Sustainable Tourism 16(5), 530-543.

Richter, L.M., A. Norman (2010) AIDS orphan tourism: a threat to young children in residential care. Vulnerable Children and Youth Studies 5(3), 217-229.

Scheyvens, R. (2002) Tourism for development: empowering communities. Essex: Prentice Hall.

Silk, J. (2004) Caring at a distance: gift theory, aid chains and social movements. Social and Cultural Geography 5(2), 229-251.

Simpson, K. (2004) 'Doing development': the gap year, volunteer-tourists and a popular practice of development. Journal of International Development 16(5), 681-692.

Simpson, K. (2005) Broad horizons? geographies and pedagogies of gap year (Unpublished PhD thesis). University of Newcastle, Newcastle, the United Kingdom.

Sin, H.L. (2009) Volunteer tourism - "involve me and I will learn"? Annals of Tourism Research 36(3), 480-501.

Sin, H.L. (2010) Who are we responsible to? locals' tales of volunteer tourism. Geoforum 41(6), 983-992.

Smith, M.D., R.S. Krannich (1998) Tourism dependence and resident attitudes. Annals of Tourism Research 25(4), 783-802.

Soontayatron, S. (2010) Socio-cultural changes in Thai beach resorts: A case study of Koh Samui Island, Thailand (Unpublished PhD thesis). Bournemouth University, Dorset, the United Kingdom.

Stoddart, H., C.M. Rogerson (2004) Volunteer tourism: the case of Habitat for Humanity South Africa. GeoJournal 60(3), 311-318.

Taylor, G. (1995) The community approach: does it really work? Tourism Management 16(7), 487-489.

Tomazos, K., R. Butler (2009) Volunteer tourism: the new ecotourism? Anatolia: An International Journal of Tourism and Hospitality Research 20(1), 196-211.

Tourism Research and Marketing (TRAM) (2008) Volunteer tourism: A global 
analysis. Arnhem, Netherlands: Vrasti, W. (2013) Volunteer tourism in the ATLAS. global south: Giving back in neoliberal times. Oxon: Routledge.

Uriely, N., A. Reichel, A. Ron (2003) Volunteering in tourism: additional thinking. Tourism Recreation Research 28(3), 57-62.

Van der Meer, K. (2007) Perspectives on ecotourism and volunteer tourism in post tsunami Khao Lak, Thailand (Unpublished Master's degree dissertation). University of Victoria, Canada.

Wearing, S. (2001) Volunteer tourism Experiences that make difference. Wallingford: CAB International.

Wearing, W., N.G. McGehee (2013) Volunteer tourism: a review. Tourism Management 38, 120-130.

Zahra, A., A.J. Mclntosh (2007) Volunteer tourism: evidence of cathartic tourist experiences. Tourism Recreation Research 32(1), 115-119. 